\title{
Lignans Extracted from Eucommia Ulmoides Oliv. Protects Against AGEs- Induced Retinal Endothelial Cell Injury
}

\author{
Ban Liu ${ }^{a, c}$ Chao-Peng Li ${ }^{b}$ Wen-Qi Wang ${ }^{b}$ Shu-Guang Song ${ }^{b}$ Xiu-Ming Liu ${ }^{b}$ \\ aDepartment of Cardiology, Shanghai Tenth People's Hospital, Tongji University School of Medicine, \\ Shanghai, 'Department of Ophthalmology, Huai' an First People's Hospital, Nanjing Medical University, \\ Huai An, 'Department of Cardiology, Shanghai Tenth People's Hospital Chongming Branch, Shanghai, \\ China
}

\section{Key Words}

Du-zhong (Eucommia ulmoides Oliv.) • Microvascular dysfunction • AGEs • Endothelial cell

\begin{abstract}
Background/Aims: Advanced glycation end products (AGEs) could elicit oxidative stress, trigger and aggravate endothelium damage in several ischemic retinopathies including diabetic retinopathy (DR). The leaves of Eucommia ulmoides O., also referred to as Tu-chung or Du-zhong, have been used for the treatment of hypertension and diabetes, showing great antioxidant activity and anti-glycation activity. Lignans is one of the main bioactive components of Eucommia ulmoides. This study mainly investigated the effect of lignans treatment on AGEs-induced endothelium damage. Methods: MTT assay, Hoechst staining, and calcein-AM/ propidium iodide (PI) staining was conducted to determine the effect of lignans treatment on endothelial cell function in vitro. Retinal trypsin digestion, Evans blue assay, isolectin staining, and western blots were conducted to determine the effect of lignans treatment on retinal microvascular function in vivo. Western blot, protein immunoprecipitation (IP), MTT assays, and enzyme activity assay was conducted to detect the effect of ligans treatment on oxidative stress response. Results: Lignans protected retinal endothelial cell against AGEs-induced injury in vitro and diabetes-induced vascular dysfunction in vivo. Lignans treatment could regulate oxidative stress response in retinal endothelial cell line, retina, and liver. Moreover, we showed that NRF2/HO-1 signaling was critical for lignans-mediated oxidative stress regulation. Conclusion: Lignans treatment could protect against endothelial dysfunction in vivo and in vitro via regulating Nrf2/HO-1 signaling. Lignans might be developed as a promising drug for the treatment of diabetes-induced microvascular dysfunction.

\section{Introduction}

Several ischemic retinopathies such as diabetic retinopathy and retinopathy of prematurity are believed to be associated with endothelial cell injury [1, 2]. A series of pathological factors, such as inflammation, oxidative stress, $\mathrm{Ca}^{2+}$ overload, are found to be 
associated with endothelial dysfunction, which could lead to the onset and development of vascular complications [3-7]. Advanced glycation end products (AGEs) are proteins or lipids that become glycated after exposure to high glucose $[8,9]$. They cause cellular dysfunction by activate AGEs receptor (RAGE). AGE-RAGE signaling could elicit oxidative stress and inflammation, trigger and aggravate endothelium damage [10]. Thus, increasing attentions have been paid to develop strategies that protect against AGEs-induced endothelial cell injury.

Eucommia ulmoides Oliv., also called Du-zhong, is an old tonic herb in the traditional Chinese medicine. It has been reported to elicit pharmacological effects on coronary blood flow, pain relief, diuresis, blood pressure and lipid metabolism [11-14]. Eucommia ulmoides extract could exhibit anti-oxidant [15], anti-hypertensive [16], anti-hyperlipidemic [17], anti-hyperglycemic [11], and anti-obesity effects [18]. The water extract from Du-zhong leaves has recently been reported to possess anti-oxidant effect and prevent oxidative stress damage and lipid-peroxidation induced by the reaction of $\mathrm{Fe}^{3+}$-EDTA $/ \mathrm{H}_{2} \mathrm{O}_{2}$ and ascorbic acid [12, 19-21]. However, the protective effect of Du-zhong on AGEs-induced endothelial dysfunction and the underlying mechanism has not been elucidated.

Previous studies have reported that 112 bioactive components have been isolated from Eucommia ulmoides, including 28 lignans, 24 iridoids, 27 phenolics, 6 steroids, 5 terpenoids, 13 flavonoids and 9 other compounds. Some of these compounds have great potential for treating human diseases. Lignans is a class of secondary metabolites consisting of two phenyl-propanoid molecules connected by 8-8' carbon atoms. Lignans and their derivatives are the key components of Eucommia ulmoides [22-24]. In this study, we investigated the effect of lignans treatment on AGEs-induced endothelial dysfunction in vivo and in vitro. Our finding revealed that lignans was a potential candidate to prevent vascular injury in ischemic retinopathies.

\section{Materials and Methods}

Preparation of lignans extract from Du-zhong (Eucommia ulmoides Oliv.)

Fresh Du-zhong leaves were collected in October 2014 (Temperature: $32 \pm 2.5^{\circ} \mathrm{C}$ ) at Chengdu, Sichuan Province, People's Republic of China. The leaves were briefly treated with steam at $100-110^{\circ} \mathrm{C}$ immediately after collection. $100 \mathrm{~g}$ powder was refluxed with $50 \%$ alcohol for $3 \mathrm{~h}$. The extract was concentrated, and then subjected to AB-8 macroporous adsorptive resins eluted using distilled water, 10\% alcohol, 30\% alcohol, and $50 \%$ alcohol $(\mathrm{V} / \mathrm{V})$. The $50 \%$ fraction was concentrated and subjected to the silica gel, and then eluted by distilled water, $20 \%$ alcohol, $40 \%$ alcohol, and $60 \%$ alcohol (V/V). It was then evaporated to dryness under reduced pressure for the total elimination of alcohol, followed by lyophilization, yielding dry residue.

Preparation and characterization of AGEs

AGEs-BSA (AGEs) was produced using D-glucose and fatty acid-free BSA. In brief, $1 \mathrm{~g}$ of BSA (40 mg/ $\mathrm{mL}$ ) was incubated with $2.2 \mathrm{~g}$ of D-glucose in $25 \mathrm{~mL}$ of PBS (pH 7.4) at $37^{\circ} \mathrm{C}$ for 90 days in dark. They were dialyzed in PBS ( $\mathrm{pH} 7.4$ ) for $96 \mathrm{~h}$ to remove the free glucose, and passed over Detoxigel columns (Thermo Fisher) to remove endotoxin. The group using BSA prepared by the same incubation without D-glucose was taken as the control. The protein concentration was determined by BCA assay and adjusted to $1 \mathrm{mg} / \mathrm{mL}$.

\section{Induction of diabetic mice and injection}

Three-month-old male C57BL/ 6 mice were housed in the light/dark $(12 \mathrm{~h} / 12 \mathrm{~h})$ controlled room at a controlled ambient temperature of $23 \pm 1.0^{\circ} \mathrm{C}$ with $50 \% \pm 5 \%$ relative humidity. Diabetes was induced by the injection of streptozocin (STZ, $70 \mathrm{mg} / \mathrm{kg}$ B.W.) freshly dissolved in a $0.1 \mathrm{M}$ citrate buffer (pH 4.3). The control group was only injected with the citrate buffer. Hyperglycemia was detected $48 \mathrm{~h}$ after injection based on blood glucose level $\geq 16.7 \mathrm{mmol} / \mathrm{L}$. Intravitreal injection of lignans was performed using a 33-gauge needle (Hamilton, Reno, NV, USA) into the vitreous body of the eye.

\section{KARGER}




\section{Cellular Physiology Cell Physiol Biochem 2016;39:2044-2054 \begin{tabular}{ll|l} 
DOI: 10.1159/000447900 & $\begin{array}{l}\text { O 2016 The Author(s). Published by S. Karger AG, Basel } \\
\text { www.karger.com/cpb }\end{array}$
\end{tabular} \\ Liu et al.: Lignans Protects Retinal Endothelial Cell}

Measurement of blood-retinal barrier breakdown using Evans blue

Blood-retinal barrier breakdown was determined using Evans blue leakage from retinal blood vessels [25-27]. In brief, the right jugular vein and right iliac artery were cannulated, and filled with heparinized saline. Evans blue was injected through the jugular vein $(50 \mathrm{mg} / \mathrm{kg}) .0 .1 \mathrm{ml}$ blood was drawn from the iliac artery to obtain plasma Evans blue concentration. After dye was circulated for $1 \mathrm{~h}$, the chest cavity was opened. Evans blue amount in the retina was quantified by spectrofluorophotometry. The concentration of Evans blue was obtained from the standard curve and normalized to the dry weight of retina.

\section{Retinal trypsin digestion}

Retinal trypsin digestion was performed according to the protocols with minor modifications [28]. The enucleated eyes were fixed in $10 \%$ neutral buffered formalin, and then incubated with $3 \%$ trypsin until the medium became cloudy. The retinas were shaken to free vascular network from adherent retinal tissue, washed in fresh water, and mounted on glass slides for dry. Finally, the retinas were stained with PAS/ hematoxylin to visualize retinal vasculature.

\section{Cells culture}

RF/6A cells were obtained from American Type Culture Collection (ATCC, Manassas, VA, USA). They were cultured in RPMI1640 medium supplemented with 10\% fetal bovine serum. Medium was replaced every 2 days. Cells were used for experiment until they reached $80-90 \%$ confluence.

\section{Cell viability}

Cell viability was determined using MTT assay [29]. Briefly, RF/6A cells $\left(5 \times 10^{4}\right.$ cells/well) were seeded into the 96-well plates and left to adhere overnight. After specific treatment, $10 \mu \mathrm{l} \mathrm{MTT}(5 \mathrm{mg} / \mathrm{ml})$ was added and incubated in dark for $3 \mathrm{~h}$ at $37^{\circ} \mathrm{C}$. After the supernatants were discarded, $100 \mathrm{mM}$ DMSO solution was added to dissolve formazan crystals. The absorbance was determined at $570 \mathrm{~nm}$ wavelength.

\section{ROS assay}

Reactive oxygen species (ROS) level was determined using ROS assay kit (Sigma) according to the manufacture's protocol. Briefly, RF/6A cells were incubated with 2, 7-dichlorofluoresceindiacetate (DCFHDA) at $37^{\circ} \mathrm{C}$ for $3 \mathrm{~h}$ and washed three times by PBS buffer. The fluorescence of 2, 7-dichlorofluorescein (DCF) was detected using a microplate reader (Molecular Devices).

\section{Western blot}

The retinas or cells were lysed in the ice-cold RIPA buffer [50 mM Tris HCl (pH 7.4), $250 \mathrm{mM} \mathrm{NaCl}$, and $1 \%$ Nonidet P-40, with a protease inhibitor cocktail]. The protein sample $(50 \mu \mathrm{g})$ was separated by sodium dodecyl sulfate poly acrylamide gel electrophoresis (SDS-PAGE, 10\%), and then transferred onto nitrocellulose membranes. The blot was blocked with $5 \%$ BSA and then incubated with the primary antibody at $4^{\circ} \mathrm{C}$ overnight. After rinsing, the membranes were incubated with horseradish-conjugated secondary antibody, reacted with enhanced chemiluminescence reagents (Pierce).

\section{Calcein-AM /PI staining}

Cell apoptosis was detected by calcein-AM/PI staining [30-32]. In brief, RF/6A cells were fixed with $70 \%$ ethanol for $15 \mathrm{~min}$. After the corresponding treatments, they were stained with calcein-AM solution (10 $\mu \mathrm{mol} / \mathrm{l})$ for $15 \mathrm{~min}$. After washing with PBS buffer, these cells were stained with PI $(10 \mu \mathrm{mol} / \mathrm{l})$ for additional $15 \mathrm{~min}$. The live cells were observed using a $490 \mathrm{~nm}$ excitation filter, whereas the dead cells were observed using a $545 \mathrm{~nm}$ excitation filter.

\section{Hoechst staining}

Hoechst staining was performed according to previously reported studies [33, 34]. RF/6A cells were fixed in $4 \%$ formaldehyde for $15 \mathrm{~min}$ at room temperature. They were then permeabilized with Triton-X 100 for additional 15 min. After washing with PBS buffer, these cells were incubated with Hoechst 33342 (100 $\mu \mathrm{g} / \mathrm{ml}$ ) for $5 \mathrm{~min}$. The stained nuclei were observed by a fluorescent microscope.

\section{KARGER}


Statistical analysis

Data were expressed as the mean \pm SEM. The groups were compared by one-way ANOVA with Tukey post hoc comparison. $P<0.05$ was considered statistically significant.

\section{Result}

Lignans protects retinal endothelial cell against AGEs-induced injury in vitro

We first examined the cytotoxic effect of AGEs on RF/6A cell function. The result showed that AGEs at the concentration of $50 \mu \mathrm{g} / \mathrm{ml}$ resulted in approximately $50 \%$ loss of cell viability (Fig. 1A). This concentration was chosen for the following experiments. Moreover, we found that lignans at the tested concentrations was safe for RF/6A cells (Fig. 1B). Notably, lignans could prevent RF/6A cells from AGEs-induced endothelial cell viability reduction (Fig. 1C). We further employed Hoechst staining (Fig. 1D) and PI/Calcein-AM staining (Fig.

Fig. 1. Lignans protects retinal endothelial cell against AGEs-induced injury in vitro. (A) RF/6A cells were treated with different concentrations of AGEs $(25,50,100$, and $150 \mu \mathrm{g} / \mathrm{ml}$ ) or left untreated for $48 \mathrm{~h}$ (Ctrl, $0 \mu \mathrm{g}$ / ml) (n=4; ${ }^{*} P=0.024,0.019$, $0.015,0.008$, respectively). (B) RF/6A cells were treated with different concentrations of lignans $(25,50$, 75 , and $100 \mu \mathrm{g} / \mathrm{ml}$ ) or left untreated for $48 \mathrm{~h}$ (Ctrl, 0 $\mu \mathrm{g} / \mathrm{ml}) \quad(\mathrm{n}=4)$. (C) $\mathrm{RF} / 6 \mathrm{~A}$ cells were pretreated with or without lignans (50 $\mu \mathrm{g}$ / $\mathrm{ml}$ ) or PBS for $6 \mathrm{~h}$, and then exposed to AGEs $(50 \mu \mathrm{g} /$ $\mathrm{mL}$ ) or left untreated for $48 \mathrm{~h}(\mathrm{Ctrl}, 0 \mu \mathrm{g} / \mathrm{ml})(\mathrm{n}=4$; ${ }^{*} P=0.021,0.042,0.023$, respectively; " $P=0.028,0.025$, respectively). Cell viability was detected using MTT method. The data was shown as the relative change compared with the Ctrl group. (D) $\mathrm{RF} / 6 \mathrm{~A}$ cells were treated as shown in Fig. 1C. Apoptotic cells were analyzed using
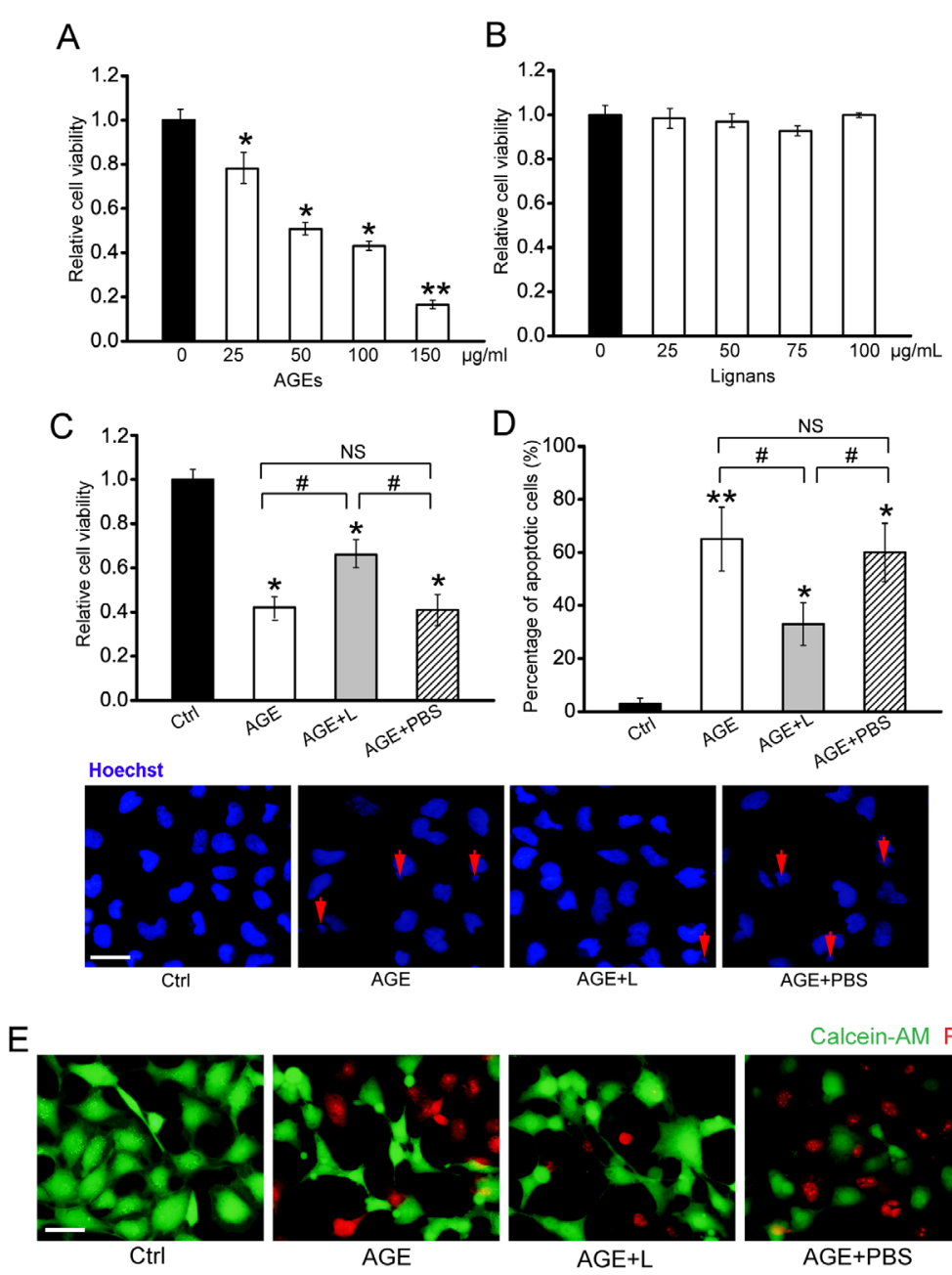

Calcein-AM PI

Hoechst staining and quantitated. The data was shown as means \pm SEM, and represented four individual experiments in which $>200$ cells were counted. Arrowheads: apoptotic nuclei; Scale bar: $20 \mu \mathrm{m}(\mathrm{n}=4$; ${ }^{*} P=0.007,0.015,0.011$, respectively; ${ }^{*} P=0.016,0.019$, respectively). (E) RF/6A cells were treated as shown in Fig. 1C. Cell apoptosis was determined by calcein-AM/PI staining. $n=4$, Scale bar: $50 \mu \mathrm{m}$. “*” indicated significant difference compared with the Ctrl group. “\#” indicated significant difference between the marked groups. NS indicted no significant difference. All data was from three independent experiments. ${ }^{*} P<0.05$, ${ }^{* *} P<0.01$, ${ }^{*} P<0.05$. 


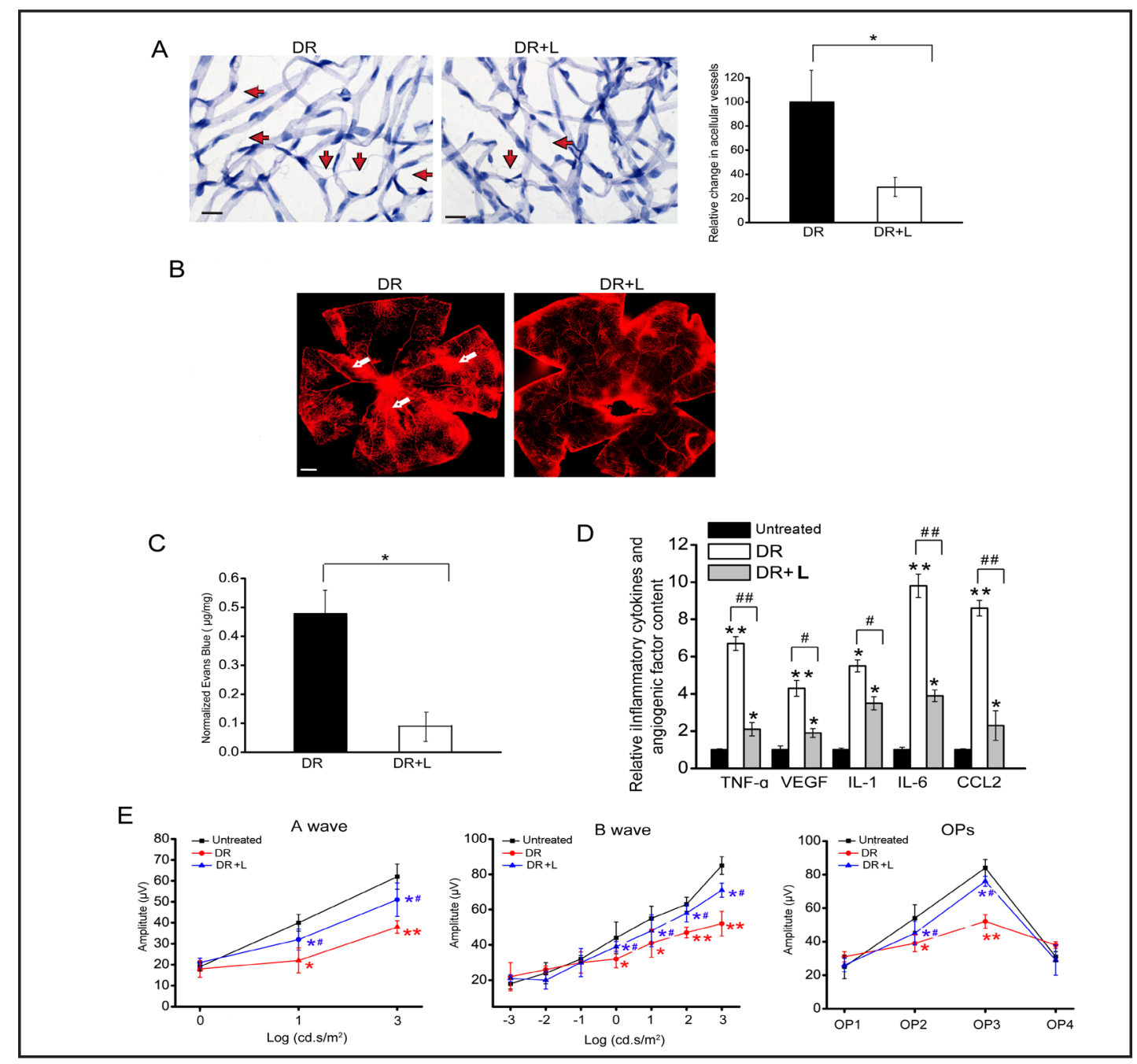

Fig. 2. Lignans protects against diabetes-induced microvascular dysfunction in vivo. (A) The diabetic mice (three-month old; male) were treated with or without lignans ( $\mathrm{L}, 10 \mu \mathrm{g} / \mathrm{mL}$ ) for 2 months. Six months after diabetes induction, retinal trypsin digestion was conducted to detect acellular capillary number. Red arrows indicated acellular capillaries. Acellular capillaries were quantified in 10 random fields per retina and averaged ( $n=6$ animals per group). Scale bar: $20 \mu \mathrm{m}$. (B) Evans blue staining was conducted to detect microvascular change. Scale bar: $100 \mu \mathrm{m}(\mathrm{n}=6$ animals per group). (C) These animals were infused with Evans blue dye for $1 \mathrm{~h}$. Quantification of Evans blue leakage was conducted in the experimental groups as shown ( $\mathrm{n}=5$ animals per group). (D) ELISAs were conducted to compare the difference of blood VEGF, TNF- $\alpha$, IL-1, IL-6, and CCL2 levels between DR and lignans-treated DR group ( $n=5$ animals per group). (E) Electroretinogram (ERG) was recorded in untreated mice, diabetic mice (DR), and lignans-treated diabetic mice (lignans, $n=6$, $20 \mathrm{mg} / \mathrm{kg}$ body weight/day). Amplitudes of a, b, and OPs waves were statistically analyzed ( $\mathrm{n}=5$ animals per group). All data were from three independent experiments. "*” indicated significant difference compared with untreated group. “\#” indicated significant difference between DR group and DR+L group. ${ }^{*} P<0.05$, ${ }^{* *} P$ $<0.01,{ }^{\#} P<0.05,{ }^{\# \#} P<0.01$.

$1 \mathrm{E})$ to determine the effect of lignans treatment on AGEs-induced RF/6A cell apoptosis. AGEs treatment significantly increased the number of apoptotic cells as shown by increased apoptotic nuclei (condensed or fragmented, Fig. 1D) and increased PI-positive cells (dying or dead cells, Fig. 1E). Lignans treatment could partially reverse AGEs-induced cell apoptosis. Taken together, these results suggest that lignans protects retinal endothelial cell against AGEs-induced injury in vitro. 


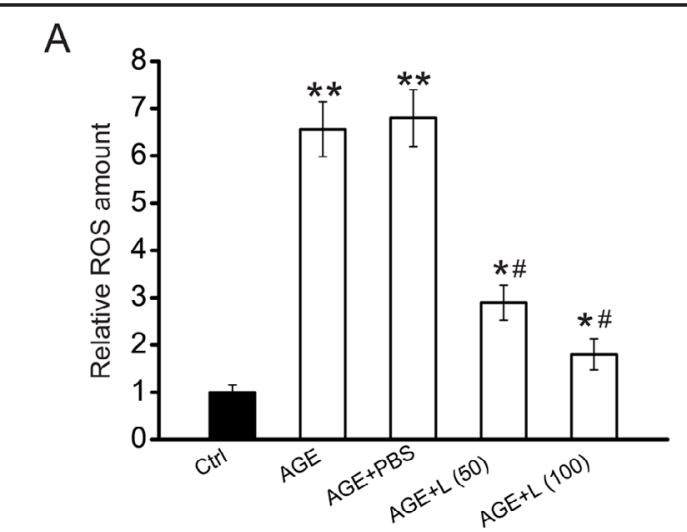

B

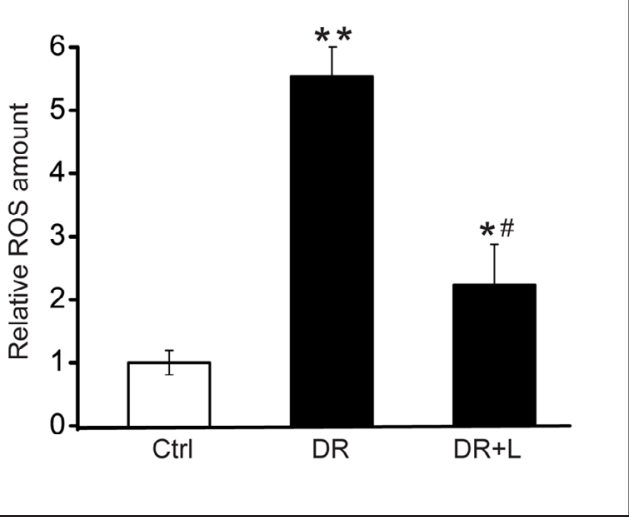

Fig. 3. Effect of lignans treatment on AGEs-induced oxidative stress in vivo and in vitro. (A) Intracellular ROS generation in RF/6A cells was determined using $2^{\prime}-7^{\prime}$-dichlorodihydrofluorescein diacetate (DCFH-DA) probe $\left(\mathrm{n}=4 ;{ }^{*} P=0.008,0.005,0.016,0.021\right.$, respectively; ${ }^{*} P=0.021,0.029$, respectively). * significant difference compared with the Ctrl group. " significant difference compared with AGE-treated group. (B) The lysates from the untreated, diabetic, lignans-treated diabetic retinas were incubated with DCFH-DA probe for ROS detection ( $\mathrm{n}=6$ animals per group; ${ }^{*} P=0.005,0.018$, respectively; ${ }^{*} P=0.018$ ). ${ }^{*}$ significant difference compared with the Ctrl group. " significant difference between diabetic retinas and lignans-treated diabetic retinas. ${ }^{*} P<0.05,{ }^{* *} P<0.01,{ }^{\#} P<0.05$. All data was from three independent experiments.

Table 1. Effect of lignans treatment on antioxidant enzyme activity in retina and liver. *Significant difference compared with the control group. " significant difference between diabetic retinas and lignans-treated diabetic retinas. ${ }^{*} P<0.05$, ${ }^{* *} P<0.01$, ${ }^{\#} P<0.05$, ${ }^{\# \#} P<0.01$

\begin{tabular}{lclll}
\hline & $\begin{array}{l}\text { Group I } \\
\text { (Control) }\end{array}$ & $\begin{array}{l}\text { Group II } \\
\text { (lignans) }\end{array}$ & $\begin{array}{l}\text { Group III } \\
\text { (Diabetic) }\end{array}$ & $\begin{array}{l}\text { Group IV } \\
\text { (Diabetic + lignans) }\end{array}$ \\
\hline $\begin{array}{l}\text { Retina } \\
\begin{array}{l}\text { Catalase } \\
\text { (U/mg protein) }\end{array}\end{array}$ & $12.36 \pm 1.87$ & $14.32 \pm 2.55^{*}$ & $10.18 \pm 2.12^{*}$ & $12.54 \pm 1.88^{\#}$ \\
$\begin{array}{l}\text { Glutathione peroxidase } \\
\text { (U/mg protein) }\end{array}$ & $17.60 \pm 1.99$ & $20.42 \pm 1.23^{*}$ & $12.81 \pm 1.56^{* *}$ & $14.58 \pm 1.98^{\# \#}$ \\
$\begin{array}{l}\text { Superoxide dismutase } \\
\text { (U/mg protein) }\end{array}$ & $15.22 \pm 1.98$ & $18.21 \pm 3.02^{*}$ & $14.54 \pm 1.71^{*}$ & $16.34 \pm 2.06^{\#}$ \\
$\begin{array}{l}\text { Liver } \\
\text { Catalase }\end{array}$ & & & $18.05 \pm 2.02^{* *}$ & $21.08 \pm 3.08^{\#}$ \\
$\begin{array}{l}\text { (U/mg protein) } \\
\text { Glutathione peroxidase } \\
\text { (U/mg protein) }\end{array}$ & $23.03 \pm 2.65$ & $26.11 \pm 3.86^{*}$ & $17.69 \pm 1.09^{* *}$ & $20.11 \pm 2.31^{\#}$ \\
$\begin{array}{l}\text { Superoxide dismutase } \\
\text { (U/mg protein) }\end{array}$ & $19.22 \pm 1.78$ & $22.16 \pm 1.09^{*}$ & $13.73 \pm 4.23^{* *}$ & $19.12 \pm 1.11^{\#}$ \\
\hline
\end{tabular}

Lignans protects against diabetes-induced vascular dysfunction in vivo

Retinal vessel dysfunction is one of important diabetes-induced complications [2]. Retinal trypsin digestion assay revealed that AGEs treatment increased the number of acellular capillaries, whereas lignans treatment could decrease the number of acellular capillaries (Fig. 2A). Isolectin-B staining and Evans blue assays showed that lignans treatment could significantly reduce AGEs-induced retinal vascular permeability (Fig. 2B and 2C). Retinal inflammation plays a critical role in diabetes-induced microvascular complication [35]. ELISA experiments showed that lignans treatment significantly decreased AGEs-induced production of inflammatory proteins, including VEGF, TNF- $\alpha$, IL-1, IL-6, and CCL2 [36, 37] (Fig. 2D). We also estimated the effect of lighans treatment on visual function using retinal electrophysiology technology. The amplitudes of a-wave, b wave, and oscillatory potentials were significantly reduced in the retinas of diabetic animals, whereas lignans could 
Fig. 4. Lignans protects against AGEs-induced cell injury via regulating oxidative stress-related protein expression. (A) RF/6A cells were treated with lignans (L, $50 \mu \mathrm{g} / \mathrm{mL}$ ) or left untreated. Western blots were performed to detect the expression of NRF2 and HO-1. GAPDH was detected as the loading control. A representative immunoblot was shown along with the quantitative data $\left(\mathrm{n}=4 ;{ }^{*} P=0.014,0.007,0.006\right.$, 0.002 , respectively). (B) $R F / 6 \mathrm{~A}$ cells were treated with lignans $(50 \mu \mathrm{g} / \mathrm{ml})$ for the indicated time periods, and the association between Keap1 and NRF2 was examined by protein-IP $(n=4)$. (C) $\mathrm{RF} / 6 \mathrm{~A}$ cells were treated as shown in Fig. 4B. NRF2 (phosphorylated and regular) and lamin-B expression in the nuclei was detected $(n=4)$. (D and E) The effect of $\mathrm{ZnPP}(10 \mu \mathrm{M})$ treatment on lignans (L, $50 \mu \mathrm{g} / \mathrm{ml})$-mediated protective effect against AGEs $(50 \mu \mathrm{g} /$ $\mathrm{mL}, 48 \mathrm{~h}$ ) in $\mathrm{RF} / 6 \mathrm{~A}$ cells was tested by MTT assays (D; $\mathrm{n}=4 ;{ }^{*} P=0.0142,0.022$, 0.026 , respectively). Light microscopy was used to observe cell morphology. Scale bar: $50 \mu \mathrm{m}(\mathrm{E})$. All data was from three independent experiments. *Significant difference compared with the Ctrl group. ${ }^{*} P<0.05,{ }^{* *} P<0.01$.

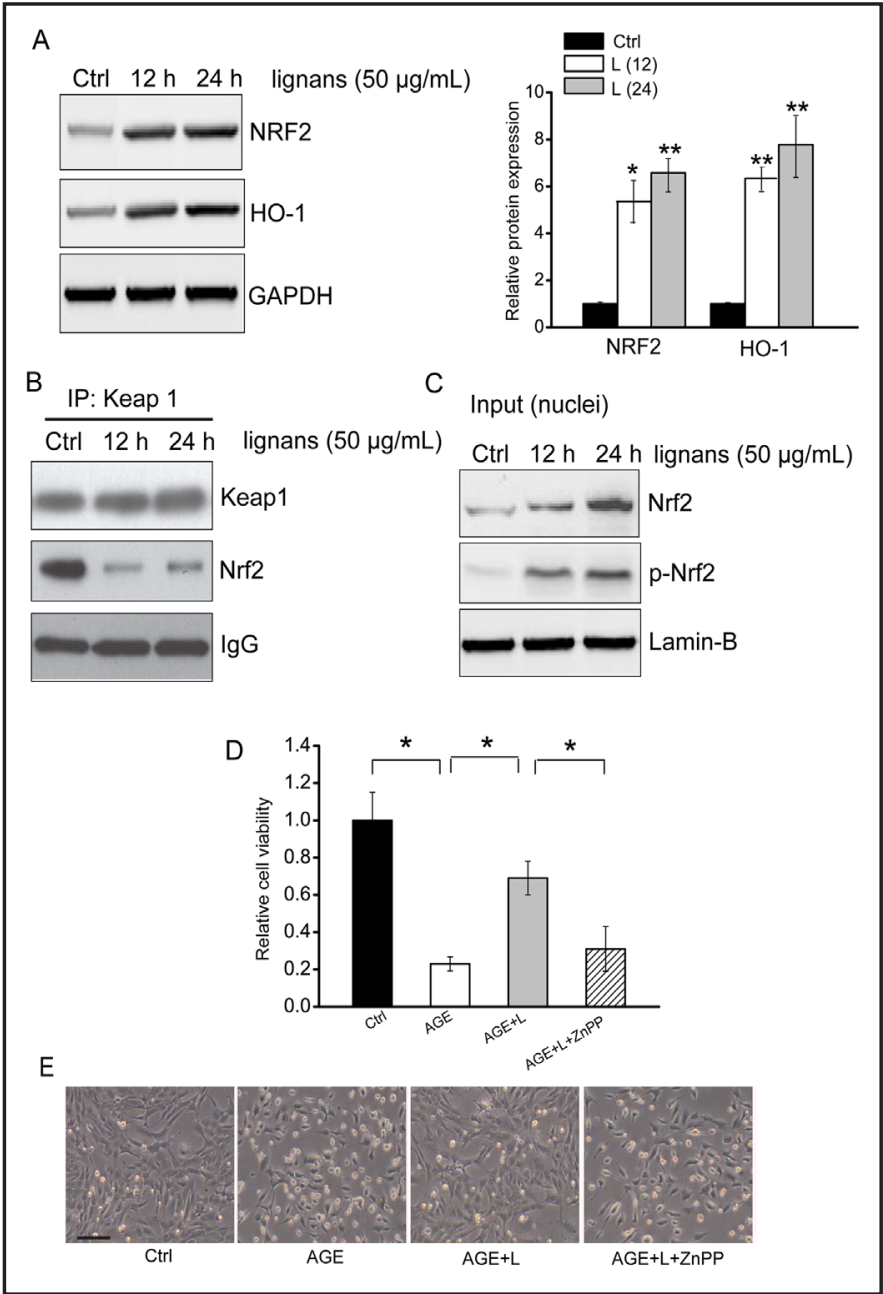

ameliorate visual function and partially reverse the decreased trend of a-wave, b-wave, and oscillatory potentials (Fig. 2E). Taken together, these results suggest that lignans protects against diabetes-induced retinal vascular dysfunction in vivo.

Effect of lignans treatment on AGEs-induced oxidative stress in vivo and in vitro

Many studies have reported that the interaction between AGEs and their receptor RAGE elicits oxidative stress and then leads to cascade signaling, such as inflammation and apoptosis responses $[10,38]$. We thus examined the effect of lignans treatment on AGEsinduced oxidative stress. Lignans treatment could decrease AGEs-induced ROS production in $\mathrm{RF} / 6 \mathrm{~A}$ cells and diabetic retinas (Fig. $3 \mathrm{~A}$ and $3 \mathrm{~B}$ ). The degree of oxidative stress is regulated by many enzymes, including catalase, glutathione peroxidase, and superoxide dismutase [39]. The result showed that lignans treatment could significantly up-regulated the activity of oxidative stress-related enzymes in both retina and liver tissues in the diabetic animals (Table 1).

Lignans protects against AGEs-induced cell injury via regulating oxidative stress-related protein expression

NRF2 and its dependent gene HO-1 are important proteins involved in regulating oxidative stress [40]. Lignans treatment significantly increased the levels of NRF2 and HO-1 protein expression (Fig. 4A). Normally, NRF2 interacts with Kelch-like ECH-associated protein 1 (KEAP1) and is thereby targeted for proteasomal degradation. Oxidative stress could oxidize redox-sensitive cysteine residues on KEAP1, resulting in the dissociation of 
KEAP1 from NRF2 [41]. Protein-IP experiments showed that lignans treatment could disrupt NRF2/Keap1 association in cytosol (Fig. 4B). We also found the phenomenon that NRF2 protein accumulation and nuclear translocation (Fig. 4C). In addition, MTT assay and cell morphology observation showed that HO-1 inhibitor, ZnPP, almost reversed the beneficial role of lignans against oxidative stress (Fig. 4D and 4E). Thus, lignans could activate NRF2/ HO-1 signaling to combat against oxidative stress.

\section{Discussion}

AGEs are proteins or lipids that become glycated after exposure to sugars. They are prevalent in diabetic vasculature and contribute to the development of vascular dysfunction [8]. AGEs have been reported to elicit a wide range of cell responses that contribute to diabetic complications, vascular and renal disease and Alzheimer's disease [42-44]. Thus, preventing AGEs-induced endothelial dysfunction could reduce or hinder diabetes-induced vascular injury. Here we revealed that lignans, the main bioactive components of Eucommia ulmoides, was a potential candidate to prevent AGEs-induced endothelial dysfunction in vivo and in vitro.

Diabetic retinopathy is an important microvascular complication of diabetes mellitus. It is usually accompanied by inflammation, neovascularization, vascular hyperpermeability, and vascular cell dysfunction [45]. Lignans treatment could alleviate diabetic-induced retinal neovascularization, vascular leakage, and inflammation in vivo. Under diabetic condition, an unceasing and excessive proliferation of endothelial cells occurs in retinal vascular system [46]. Thus, any factors altering endothelial cell function could lead to retinal microvascular dysfunction. Lignans treatment could significantly regulate endothelial cell viability and high glucose-induced cell apoptosis in vitro. Thus, it is not surprised that lignans is a promising drug for the treatment of microvascular dysfunction.

Oxidative stress plays an important role in the development of diabetes-related vascular complications. The metabolic abnormalities of diabetes cause mitochondrial superoxide overproduction in endothelial cells [47]. Increased superoxide production could lead to increased formation of AGEs and increased expression of the receptor for AGEs and its activating ligands $[38,48]$. Lignans treatment could decrease ROS production in RF/6A cells and diabetic retinas. Moreover, lignans treatment could significantly up-regulated the activity of oxidative stress-related enzymes. Decreased superoxide production would lead to decreased formation of AGEs, which could decrease AGEs-induced endothelial dysfunction in vivo and in vitro.

NRF2 is an important transactivator of several protective and metabolic enzymes, such as $\gamma$-glutamylcysteine ligase, glutathione reductase (GSHRd), aldo-keto reductase (AKRd), glutathione transferases, quinone reductase (NQO1), HO-1 [49, 50]. NRF2-linked gene expression plays a critical role in the protection of cells against oxidative stress. Lignans treatment could lead to the activation of Nrf2/ARE signaling. Inhibition of NRF2/ HO-1 signaling could decrease the protective effect of lignans on AGEs-induced endothelial dysfunction.

In conclusion, we demonstrated that lignans treatment could protect against on AGEsinduced endothelial dysfunction in vivo and in vitro via regulating Nrf2/HO-1 signaling. This study provides significant experimental data for developing lignans as a therapeutic agent for the prevention and treatment of diabetes-related vascular complication.

\section{Disclosure Statement}

None declared. 


\section{Cellular Physiology Cell Physiol Biochem 2016;39:2044-2054 and Biochemistry \begin{tabular}{l|l} 
DOI: 10.1159/000447900 & (c) 2016 The Author(s). Published by S. Karger AG, Basel \\
www.karger.com/cpb
\end{tabular}}

Liu et al.: Lignans Protects Retinal Endothelial Cell

\section{Reference}

1 Sapieha P, Joyal JS, Rivera JC, Kermorvant-Duchemin E, Sennlaub F, Hardy P, Lachapelle P, Chemtob S: Retinopathy of prematurity: understanding ischemic retinal vasculopathies at an extreme of life. J Clin Invest 2010;120:3022-3032.

2 Brownlee M: Biochemistry and molecular cell biology of diabetic complications. Nature 2001;414:813-820.

3 Brownlee M: The pathobiology of diabetic complications a unifying mechanism. Diabetes 2005;54:16151625.

4 Van Hecke M, Dekker J, Nijpels G, Moll A, Heine R, Bouter L, Polak B, Stehouwer C: Inflammation and endothelial dysfunction are associated with retinopathy: the hoorn study. Diabetologia 2005;48:13001306.

5 Cai H, Harrison DG: Endothelial dysfunction in cardiovascular diseases: The role of oxidant stress. Circ Res 2000;87:840-844.

6 Hong Q Qi K, Feng Z, Huang Z, Cui S, Wang L, Fu B, Ding R, Yang J, Chen X: Hyperuricemia induces endothelial dysfunction via mitochondrial $\mathrm{Na}+/ \mathrm{Ca} 2+$ exchanger-mediated mitochondrial calcium overload. Cell Calcium 2012;51:402-410.

7 Shenouda SM, Widlansky ME, Chen K, Xu G, Holbrook M, Tabit CE, Hamburg NM, Frame AA, Caiano TL, Kluge MA: Altered mitochondrial dynamics contributes to endothelial dysfunction in diabetes mellitus. Circulation 2011;124:444-453.

8 Schmidt AM, Yan SD, Wautier JL, Stern D. Activation of receptor for advanced glycation end products: a mechanism for chronic vascular dysfunction in diabetic vasculopathy and atherosclerosis. Circ Res 1999;84:489-497.

9 Goldin A, Beckman JA, Schmidt AM, Creager MA: Advanced glycation end products sparking the development of diabetic vascular injury. Circulation 2006;114:597-605.

10 Bierhaus A, Hofmann MA, Ziegler R, Nawroth PP: AGEs and their interaction with AGE-receptors in vascular disease and diabetes mellitus. I. The age concept. Cardiovasc Res 1998;37:586-600.

11 Lee MK, Kim MJ, Cho SY, Park SA, Park KK, Jung UJ, Park HM, Choi MS: Hypoglycemic effect of du-zhong (Eucommia ulmoides oliv.) leaves in streptozotocin-induced diabetic rats. Diabetes Res Clin Pr 2005;67:2228.

12 Hsieh CL, Yen GC: Antioxidant actions of du-zhong (Eucommia ulmoides oliv.) toward oxidative damage in biomolecules. Life Sci 2000;66:1387-1400.

13 Nakazawa Y: Effect of eucommia leaf (Eucommia ulmoides oliver leaf; du-zhong yge) extract on blood pressure. J Nat Med 1997;51:392-398.

14 Kwon SH, Kim MJ, Ma SX, You IJ, Hwang JY, Oh JH, Kim SY, Kim HC, Lee SY, Jang CG: Eucommia ulmoides oliv. Bark. Protects against hydrogen peroxide-induced neuronal cell death in sh-sy5y cells. J Ethnopharmacol 2012;142:337-345.

15 Yen GC, Hsieh CL: Reactive oxygen species scavenging activity of du-zhong (Eucommia ulmoides oliv.) and its active compounds. J Agr Food Chem 2000;48:3431-3436.

16 Hosoo S, Koyama M, Kato M, Hirata T, Yamaguchi Y, Yamasaki H, Wada A, Wada K, Nishibe S, Nakamura K: The restorative effects of Eucommia ulmoides oliver leaf extract on vascular function in spontaneously hypertensive rats. Molecules 2015;20:21971-21981.

17 Metori K, Ohashi S, Takahashi S, Tamura T: Effects of du-zhong leaf extract on serum and hepatic lipids in rats fed a high-fat diet. Biol Pharm Bull 1994;17:917-920.

18 Hirata T, Kobayashi T, Wada A, Ueda T, Fujikawa T, Miyashita H, Ikeda T, Tsukamoto S, Nohara T: Antiobesity compounds in green leaves of Eucommia ulmoides. Bioorg Med Chem Lett 2011;21:1786-1791.

19 Yen GC, Hsieh CL: Inhibitory effects of du-zhong (Eucommia ulmoides oliv.) against low-density lipoprotein oxidative modification. Food Chem 2002;77:449-456.

20 Yen GC, Hsieh CL: Antioxidant activity of extracts from du-zhong (Eucommia ulmoides) toward various lipid peroxidation models in vitro. J Agr Food Chem 1998;46:3952-3957.

21 Lin J, Fan YJ, Mehl C, Zhu JJ, Chen H, Jin LY, Xu JH, Wang HM: Eucommia ulmoides oliv. Antagonizes H2O2induced rat osteoblastic MC3T3-E1 apoptosis by inhibiting expressions of caspases 3, 6, 7, and 9. J Zhejiang Univ Sci B 2011;12:47-54. 


\section{Cellular Physiology Cell Physiol Biochem 2016;39:2044-2054

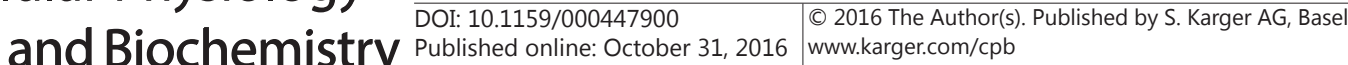

Liu et al.: Lignans Protects Retinal Endothelial Cell

22 Jing X, Huang WH, Tang YJ, Wang YQ, Li H, Tian YY, Chen Y, Zhou HH, Ouyang DS: Eucommia ulmoides oliv. (du-zhong) lignans inhibit angiotensin II-stimulated proliferation by affecting P21, P27, and Bax expression in rat mesangial cells. Evid Based Complement Alternat Med 2015;987973:10.

23 He X, Wang J, Li M, Hao D, Yang Y, Zhang C, He R, Tao R: Eucommia ulmoides oliv.: Ethnopharmacology, phytochemistry and pharmacology of an important traditional chinese medicine. J Ethnopharmacol 2014;151:78-92.

24 Zhang R, Pan YL, Hu SJ, Kong XH, Juan W, Mei QB: Effects of total lignans from Eucommia ulmoides barks prevent bone loss in vivo and in vitro. J Ethnopharmacol 2014;155:104-112.

25 Liu J, Yao J, Li X, Song Y, Wang X, Li Y, Yan B, Jiang Q: Pathogenic role of IncRNA-MALAT1 in endothelial cell dysfunction in diabetes mellitus. Cell Death Dis 2014;5:e1506.

26 Mysona BA, Al-Gayyar MM, Matragoon S, Abdelsaid MA, El-Azab MF, Saragovi HU, El-Remessy AB: Modulation of p75NTR prevents diabetes-and proNGF-induced retinal inflammation and blood-retina barrier breakdown in mice and rats. Diabetologia 2013;56:2329-2339.

27 Yan B, Yao J, Liu JY, Li XM, Wang XQ Li YJ, Tao ZF, Song YC, Chen Q Jiang Q: IncRNA-MIAT regulates microvascular dysfunction by functioning as a competing endogenous RNA. Circ Res 2015;116:1143-1156.

28 Dong LF, Yao J, Wang XQ, Shan K, Yang H, Yan B, Jiang Q. Lenalidomide, an anti-tumor drug, regulates retinal endothelial cell function: implication for treating ocular neovascular disorder. Biochem Biophys Res Commun 2015;465:678-684.

29 Walter S, Letiembre M, Liu Y, Heine H, Penke B, Hao W, Bode B, Manietta N, Walter J, Schulz-Schüffer W: Role of the toll-like receptor 4 in neuroinflammation in Alzheimer's disease. Cell Physiol Biochem 2007;20:947-956.

30 Caspi O, Lesman A, Basevitch Y, Gepstein A, Arbel G, Habib IHM, Gepstein L, Levenberg S: Tissue engineering of vascularized cardiac muscle from human embryonic stem cells. Circ Res 2007;100:263-272.

31 Zhang Y, Gong J, Xing T, Zheng S, Ding W: Autophagy protein p62/SQSTM1 is involved in HAMLET-induced cell death by modulating apotosis in U87MG cells. Cell Death Dis 2013;4:e550.

32 Lin C, Chen T, Yang L, Shih CM: Resveratrol protects astrocytes against traumatic brain injury through inhibiting apoptotic and autophagic cell death. Cell Death Dis 2014;5:e1147.

33 Ch'Ng J, Kotturi S, Chong AG, Lear MJ, Tan KS: A programmed cell death pathway in the malaria parasite Plasmodium falciparum has general features of mammalian apoptosis but is mediated by clan CA cysteine proteases. Cell Death Dis 2010;1:e26.

34 Guadagno J, Xu X, Karajgikar M, Brown A, Cregan S: Microglia-derived TNF $\alpha$ induces apoptosis in neural precursor cells via transcriptional activation of the Bcl-2 family member puma. Cell Death Dis 2013;4:e538.

35 Yan SF, Ramasamy R, Naka Y, Schmidt AM: Glycation, inflammation, and RAGE a scaffold for the macrovascular complications of diabetes and beyond. Circ Res 2003;93:1159-1169.

36 Chitranshi N, Gupta V, Kumar S, Graham SL: Exploring the molecular interactions of 7, 8-dihydroxyflavone and its derivatives with TrkB and VEGFR2 proteins. Int J Mol Sci 2015;16:21087-21108.

37 You Y, Gupta VK, Li JC, Klistorner A, Graham SL: Optic neuropathies: characteristic features and mechanisms of retinal ganglion cell loss. Rev Neurosci 2013;24:301-321.

38 Giacco F, Brownlee M: Oxidative stress and diabetic complications. Circ Res 2010;107:1058-1070.

39 Harris ED: Regulation of antioxidant enzymes. FASEB J 1992;6:2675-2683.

40 Kensler TW, Wakabayashi N, Biswal S: Cell survival responses to environmental stresses via the Keap1Nrf2-are pathway. Annu Rev Pharmacol Toxicol 2007;47:89-116.

41 Hayes JD, McMahon M: Nrf2 and Keap1 mutations: permanent activation of an adaptive response in cancer. Trends Biochem Sci 2009;34:176-188.

42 Münch G, Thome J, Foley P, Schinzel R, Riederer P: Advanced glycation endproducts in ageing and alzheimer's disease. Brain Res Rev 1997;23:134-143.

43 Makita Z, Bucala R, Rayfield E, Fuh H, Manogue K, Cerami A, Viassara H, Friedman E, Kaufman A, Korbet S: Reactive glycosylation endproducts in diabetic uraemia and treatment of renal failure. Lancet 1994;343:1519-1522.

44 Brownlee M, Michael: Advanced protein glycosylation in diabetes and aging. Annu Rev Med 1995;46:223234.

45 Joussen AM, Poulaki V, Le ML, Koizumi K, Esser C, Janicki H, Schraermeyer U, Kociok N, Fauser S, Kirchhof B: A central role for inflammation in the pathogenesis of diabetic retinopathy. FASEB J 2004;18:1450-1452. 


\section{Cellular Physiology Cell Physiol Biochem 2016;39:2044-2054 \begin{tabular}{ll|l} 
DOI: 10.1159/000447900 & $\begin{array}{l}\text { O 2016 The Author(s). Published by S. Karger AG, Basel } \\
\text { www.karger.com/cpb }\end{array}$ \\
\hline
\end{tabular}}

Liu et al.: Lignans Protects Retinal Endothelial Cell

46 Harrison DG: Cellular and molecular mechanisms of endothelial cell dysfunction. J Clinic Invest 1997;100:2153.

47 Jay D, Hitomi H, Griendling KK: Oxidative stress and diabetic cardiovascular complications. Free Radical Bio Med 2006;40:183-192.

48 Yan SF, Ramasamy R, Schmidt AM: Mechanisms of disease: Advanced glycation end-products and their receptor in inflammation and diabetes complications. Nat Rev Endocrinol 2008;4:285-293.

49 Chen XL, Dodd G, Thomas S, Zhang X, Wasserman MA, Rovin BH, Kunsch C: Activation of NRF2/are pathway protects endothelial cells from oxidant injury and inhibits inflammatory gene expression. Am J Physiol 2006;290:H1862-H1870.

50 Zakkar M, Van der Heiden K, Luong LA, Chaudhury H, Cuhlmann S, Hamdulay SS, Krams R, Edirisinghe I, Rahman I, Carlsen H: Activation of NRF2 in endothelial cells protects arteries from exhibiting a proinflammatory state. Arterioscl Throm Vas 2009;29:1851-1857. 